\title{
Correction to: Transoral endoscopic thyroidectomy for thyroid carcinoma: outcomes and surgical completeness in 150 single-surgeon
} \section{cases}

\author{
Jong-hyuk Ahn ${ }^{1} \mathbb{D} \cdot \operatorname{Jin}$ Wook $\mathrm{Yi}^{1,2}$
}

Published online: 5 June 2019

(c) Springer Science+Business Media, LLC, part of Springer Nature 2019

\section{Correction to: Surgical Endoscopy https://doi.org/10.1007/s00464-019-06841-8}

Publisher's Note Springer Nature remains neutral with regard to jurisdictional claims in published maps and institutional affiliations.

The Acknowledgment was omitted from this article and appears below:

Acknowledgement This work was supported by INHA UNIVERSITY HOSPITAL Research Grant.

\section{Jin Wook Yi}

gnsljw@gmail.com

1 Department of Surgery, Inha University Hospital, 27,

Inhang-ro, Jung-gu, Incheon, Republic of Korea

2 Department of Surgery, Seoul National University Hospital,

Seoul National University College of Medicine, Seoul,

Republic of Korea 